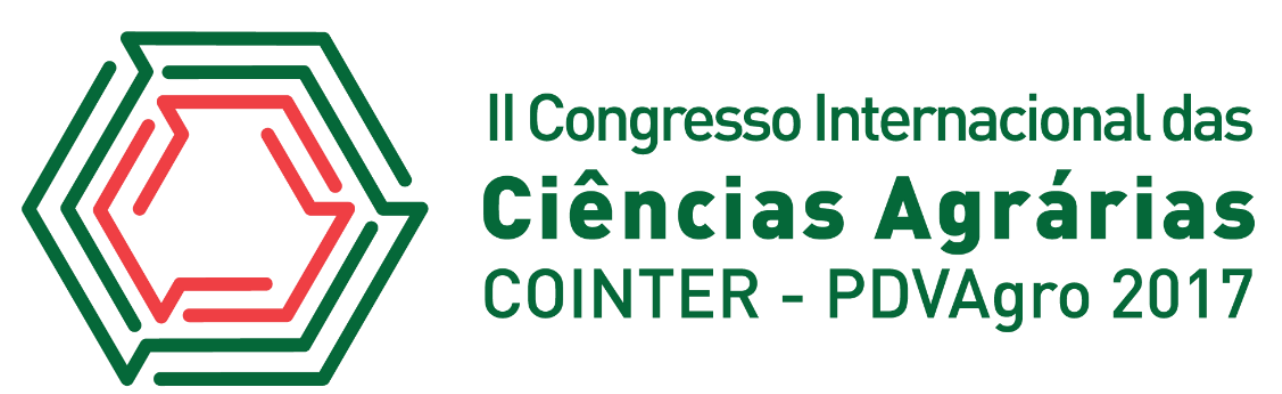

\title{
EFEITO DO ESTRESSE SALINO NA GERMINAÇÃO E DESENVOLVIMENTO INICIAL DE PLÂNTULAS DE FEIJÃO CAUPI
}

\author{
Apresentação: Pôster
}

Railany Brito de Lucena ${ }^{1}$; Salenilza Pires de Almeida ${ }^{2}$; Bruna Marques Felipe ${ }^{3}$; Juliana Joice Pereira Lima ${ }^{4}$; Edilza Maria Felipe Vásquez ${ }^{5}$.

\section{Introdução}

O feijão-caupi é uma leguminosa que apresenta fundamental importância social e econômica para o Nordeste do Brasil, constituindo-se em uma das principais fontes proteicas na alimentação da população de baixa renda. O consumo na forma de grãos secos ou verdes, como hortaliça e vagens, tem aumentado nos últimos anos, tornando-se uma excelente alternativa, não apenas de sobrevivência, mas de comercialização para os agricultores (OLIVEIRA et al, 2001).

A salinidade do solo é um dos fatores que mais afetam a germinação das sementes, a formação de mudas, o crescimento e desenvolvimento das plantas e a produção das culturas.

O objetivo deste trabalho foi avaliar o efeito do estresse salino na germinação e desenvolvimento de sementesde Feijão-caupi.

\section{Fundamentação Teórica}

O teste de germinação é o principal parâmetro utilizado para a avaliação da qualidade fisiológica das sementes e permite conhecer o potencial de germinação de um lote em condiçõesfavoráveis (CARVALHO e NAKAGAWA, 2000).

\footnotetext{
${ }^{1}$ Agronomia, Universidade Federal do Cariri, railanybrito@hotmail.com

${ }^{2}$ Agronomia, Universidade Federal do Cariri, as.anna.maria@gmail.com

${ }^{3}$ Agronomia, Universidade Federal do Cariri, brunnamarques40@hotmail.com

${ }^{4}$ Prof. Dra. em Fitotecnia, Universidade Federal do Cariri julianajoicelima@yahoo.com.br

${ }^{6}$ Prof. Dra. Em Fitotecnia, Universidade Federal do Cariri, edilza.felipe@ufca.edu.br
} 
Nas sementes a salinidade afeta a porcentagem de germinação e os caracteres ligados ao vigor afetando o estabelecimento de plântulas (Sivritepe et al., 2003), reduzindo a velocidade de emergência, na uniformidade, na emergência total, no tamanho inicial e no estabelecimento de estande adequado, fatores que podem influenciar na acumulação de matéria seca e, assim, afetar a produtividade (Scheeren et al., 2010).

\section{Metodologia}

O experimento foi realizado no período de junho de 2017, no Laboratório de Biologia da Universidade Federal do Cariri - UFCA, situada no município do Crato-Ce.

As sementes de feijão caupi da variedade Manteiga foram adquiridas junto a produtores da região. Foram utilizadasquatro amostras de 25 sementes por tratamento, as quais foram submetidas as concentrações de cloreto de sódio $(\mathrm{NaCl})$ de $0,0-0,2-0,4-0,6$ e -1,2 $\mathrm{MPa}$. As sementes foram colocadas entre folhas umedecidas com soluções nas concentrações acima citadas e mantidos em germinador do tipo B.O.D. à temperatura de $30^{\circ} \mathrm{C}$.

As variáveis analisadas foram germinação, anormais e mortas após 8 dias, de acordo com Brasil (2009).

Para o teste de germinação foram computadas diariamente e no mesmo horário as sementes germinadas para cálculo do Índice de Velocidade de Germinação (IVG), com emprego da fórmula proposta por Maguire (1962).

$$
I V G=E_{1} / N_{1}+E_{2} / N_{2}+\ldots+E_{m} / N_{n}
$$

Onde: $\mathrm{E}_{1}, \mathrm{E}_{2}, \ldots, \mathrm{E}_{\mathrm{m}}=\mathrm{n}^{\mathrm{o}}$ de plântulas emergidas, computadas na primeira, segunda, última contagem $\mathrm{N}_{1}, \mathrm{~N}_{2}, \ldots, \mathrm{N}_{\mathrm{n}}=\mathrm{n}^{\mathrm{o}}$ de dias de semeadura à primeira, segunda, ..., última contagem

\section{Para obtenção do Tempo Médio de Germinação (TM) e Sincronização da} germinação (U) utilizou-se as fórmulas propostas por Labouriau (1983) como segue:

$$
\mathbf{T M}=(\Sigma \mathbf{n i t i}) / \Sigma \mathbf{n i}
$$

Onde: $\mathrm{TM}=$ tempo médio de germinação; $\mathrm{ni}=$ número de sementes germinadas por dia; $\mathrm{t} i=$ tempo de incubação (dias).

$\mathbf{F r}=\mathbf{n i} / \Sigma \mathbf{n i}$

onde: $\mathrm{Fr}=$ freqüência relativa de germinação; ni= número de sementes germinadas por dia; $\Sigma$ ni= número total de sementes germinadas.

$\mathrm{U}=-\Sigma$ filog $_{2} \mathbf{f i}$ 
Foi usado o delineamento inteiramente casualizado, com quatro tratamentos e quatro repetições. Os dados foram submetidos à análise de variância pelo teste $\mathrm{F}$ e as médias dos tratamentos comparadas pelo teste de Tukey e análise de regressão, a 5\% de probabilidade

\section{Resultados e Discussões}

Os resultados da análise de variância e a curva da equação de regressão (Gráfico1) mostram que houve efeito significativo $(\mathrm{p}<0,05)$ dos níveis de salinidade sobre a percentagem de germinação de sementes de feijão-caupi. A percentagem média de germinação do nível de 0,0 MPa foi de 82\% contra $0 \%$ do nível mais alto de salinidade 1,2 Mpa. Tais efeitos podem ser explicados, uma vez que altos níveis de salinidade reduzem a disponibilidade de água necessária para a embebição, provocatoxidade pelo acúmulo de certos íons e dificultam o processo nutricional, impedindo, por exemplo, a absorção de K, cofator de inúmeras enzimas responsáveis pela fotossíntese e respiração, fundamental para o fornecimento de energia para os processos metabólicos da germinação(Taiz\&Zeiger 2006)).

Gráfico 1. Efeito de diferentes níveis de salinidade na percentagem de germinação normal de feijão- caupi (Vigna unguiculata (L) Walp). Fonte Própria

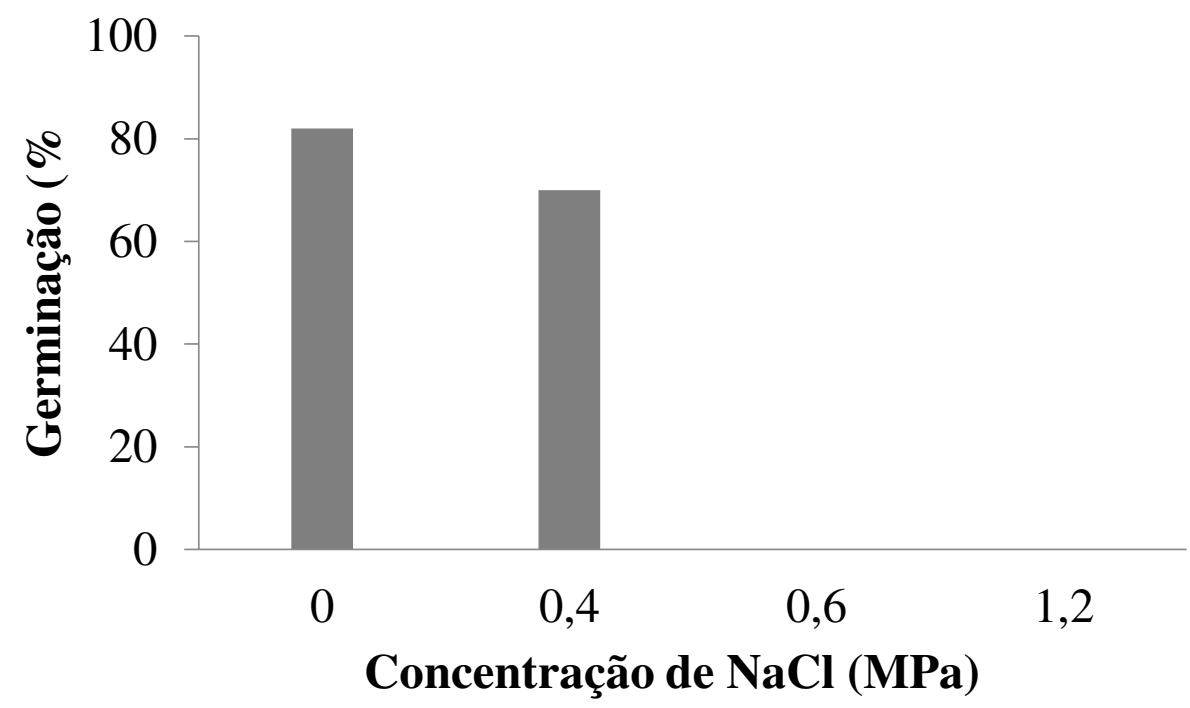

Para a variável sementes mortas, houve aumento significativo de acordo com o aumento do nível de salinidade (Gráfico 2), indo de $2 \%$ com uma concentração de 0,0 MPa para $65 \%$ com a dosagem de 1,2 MPa. 
Trabalhando com feijão-caupi, Silva et al. (2009) relataram resultados semelhantes, pois a salinidade afetou todas as variáveis analisadas, tendo influenciado, portanto, o desenvolvimento da cultura em questão. Estudos desenvolvidos por Murillo-Amador et al. (2006) demonstraram que o aumento da salinidade diminuiu a percentagem de emergência das plântulas, sendo este efeito significativamente dependente do genótipo.

Para plântulas anormais conforme mostra o (Gráfico3) o aumento da concentração salina também teve efeito significativo, contudo, a diferença do nível de salinidade de 0,6 MPa com $79 \%$ e 1,2 MPa com 15\% de plântulas anormais foram, decorrentes de um provável dano de embebição.

Em condições de excesso de água, a semente poderá absorver água muito rapidamente, ocasionando rupturas em seus tecidos (Hobbs e Obendorf, 1972).

Gráfico 2. Efeito de diferentes níveis de salinidade na percentagem de sementes mortas de feijão- caupi (Vigna unguiculata (L) Walp). Fonte Própria

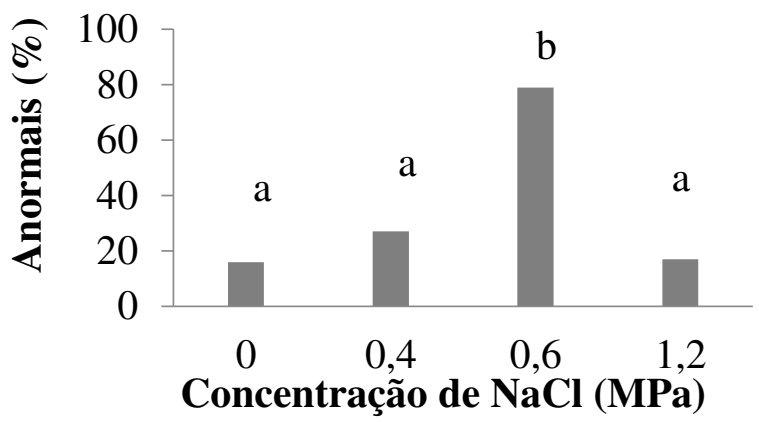

Gráfico 4. Efeito de diferentes níveis de salinidade no Índice de velocidade de germinação (IVG) de sementes de feijão- caupi (Vigna unguiculata (L) Walp). Fonte Própria

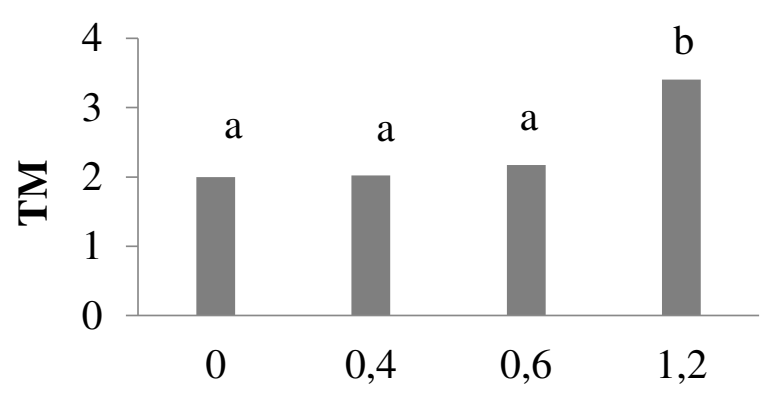

Concentração de $\mathrm{NaCl}$ (MPa)
Gráfico 3. Efeito de diferentes níveis de salinidade na percentagem de sementes anormais de feijão- caupi (Vigna unguiculata (L) Walp). Fonte Própria

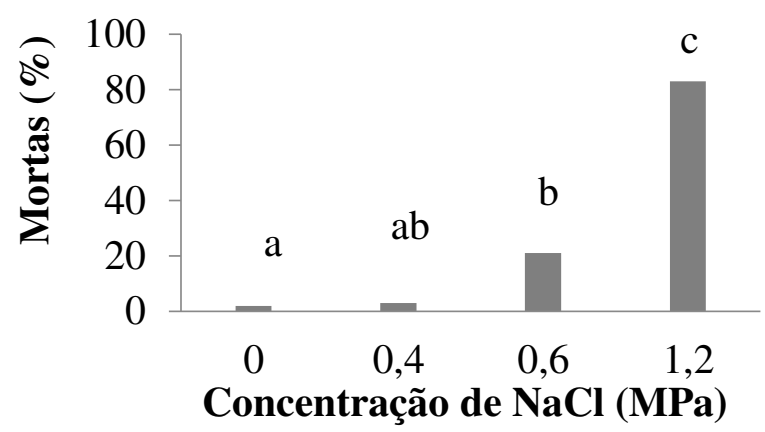

Gráfico 5. Efeito de diferentes níveis de salinidade no Tempo Médio de germinação (TM) de sementes de feijão- caupi (Vigna unguiculata (L) Walp). Fonte Própria

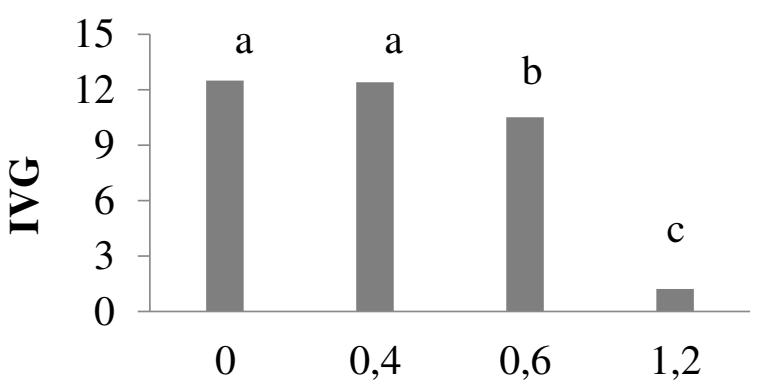

Concentração de $\mathrm{NaCl}$ (MPa) 
O índice de velocidade de germinação das sementes foi, também, influenciado pelo aumento das concentrações até $-1,2$, onde atingiu seu ponto mínimo $(1,22)$. O maior índice $(12,4)$ foi registrado quando as sementes foram submetidas ao tratamento de concentração 0,4 (Figura 4).

Constatou-se na Figura, que a medida que as concentrações de $\mathrm{NaCl}$ aumentaram o Tempo Médio de Germinação diminuiu.

\section{Conclusões}

A germinação e o vigor de sementes de feijão caupi variedade manteiga são afetados negativamente pelo aumento da salinidade a partir do potencial de -0,6 MPa.

\section{Referências}

Barreto, H. B. F.; Freitas, R. M. O. de; Oliveira, L. A. de. A.; Araujo, J. A. de M.; Costa, E. M. da. Efeito da irrigação com água salina na germinação de sementes de sabiá (Mimosa caesalpiniifoliaBenth). Revista Verde de Agroecologia e Desenvolvimento Sustentável, v.5, p.125$130,2010$.

CARVALHO, N. M.; NAKAGAWA, J. Sementes: ciência, tecnologia e produção. 4. ed. Jaboticabal: Funep, 588 p.2000.

HOBBS, P.R.; OBENDORF, R.L. Interaction of initial seed moisture and imbibitional temperature on germination and productivity of soybean. Crop Science, Madison, v.13, p.664-667, 1972.

MARCOS FILHO, J. Fisiologia de sementes de plantas cultivadas. Piracicaba: FEALQ. 495p. 2005.

Murillo-Amador, B.; Troyo-Dieguez, E.; Gárcia-Hernandez, J. L.; Lópes-Agular, R.; Ávila-Serrano, N. Y.; Zamora-Salgado, S.; Rueda-Puente, E. O.; Kaya, C. Effec to $\mathrm{NaCl}$ salinity in the genotypic variation of cowpea (Vigna unguiculata) during $\mathrm{eaR}_{\mathrm{L}} \mathrm{y}$ vegetative growth. Revista Scientia Horticulturae, v.108, p.423-431, 2006.

OLIVEIRA, A.P.; ARAÚJO, J.S.; ALVES, E.U.; NORONHA, M.A.S.; CASSIMIRO, C.M.; MENDONÇA, F.G. Rendimento de feijão caupi cultivado 22 com esterco bovino e adubo mineral. Horticultura Brasileira, Brasília, v.19, n.1, p.81-84, 2001.

Scheeren, B. R.; Peske, S. T.; Schuch, L. O. B.; Barros, A. C. A. Qualidade fisiológica e produtividade de sementes de soja. Revista Brasileira de Sementes, v.32, p.35-41, 2010.

Sivritepe, N; Sivritepe, H. O.; Eris, A. The effect of $\mathrm{NaCl}$ priming on salt tolerance in melon seedling grown under saline conditions. Scientae Horticulturae, v.97, p.229-237, 2003.

Silva, F. E. O.; Maracajá, P. B.; Medeiros, J. F.; Oliveira, F. A.; Oliveira, M. K. T. Desenvolvimento vegetativo de feijão caupi irrigado com água salina em casa de vegetação. Revista Caatinga, v.22, p.156-159, 2009.

TAIZ, L.; ZEIGER, E. Fisiologia vegetal. Porto Alegre: Artmed, 2006. 719p. 